\title{
Impact of Plant Breeding on the Genetic Diversity of Cultivated Strawberry as Revealed by Expressed Sequence Tag-derived Simple Sequence Repeat Markers
}

\author{
David Jesús Gil-Ariza, Iraida Amaya, José Manuel López-Aranda, \\ and José Federico Sánchez-Sevilla ${ }^{1}$ \\ Instituto de Investigación y Formación Agraria y Pesquera (IFAPA), Junta de Andalucia, Area de \\ Mejora y Biotecnologia, Cortijo de la Cruz, Málaga, Malaga 29140 Spain
}

Miguel Ángel Botella and Victoriano Valpuesta

Dep. Biología Molecular y Bioquímica, Universidad de Málaga, Málaga 29071 Spain

AdDitional INDEX words. Fragaria $\times$ ananassa, EST, resources, population structure, AMOVA

\begin{abstract}
Unlike other important crops analyzed so far for genetic diversity and population structure, the brief history and particularities of the genetics of the cultivated strawberry (Fragaria $\times$ ananassa Duchesne) have limited its genetic characterization. The genomic composition and the pattern of inheritance have not been fully elucidated, although a number of studies have suggested a highly diploidized genome. In this study, the similarity relationships and structure of 92 selected strawberry cultivars with widely diverse origins have been established using simple sequence repeat (SSR) markers derived from expressed sequence tags (EST-SSR markers). Genetic analysis performed by the unweighted pair group method with arithmetic mean clustering revealed a distribution according to both date of cultivar release and breeding for a specific climatic adaptation. Additionally, a model-based clustering approach identified three populations among the strawberry cultivars with an overall $F_{S T}$ value of 0.15 to 0.16 . Both analyses support a limited differentiation of modern cultivars, most probably as a consequence of the methodology of strawberry breeding. Interestingly, the collection of strawberry cultivars here analyzed showed comparable genetic differentiation to that observed in natural populations of Fragaria chiloensis (L.) Mill., one of its wild ancestors. Our results suggest that breeding has produced a small but significant reduction on the genetic diversity of $F$. $\times$ ananassa. The panel of 10 EST-SSRs described in this work provided an extremely low probability of confusion (less than $10^{-11}$ ), offering an efficient and accurate method for cultivar identification.
\end{abstract}

Strawberry is an important perennial fruit crop worldwide with production in 2006 of over 4 million $t$ (Food and Agriculture Organization of the United Nations, 2008). The cultivated strawberry is octoploid $(2 n=8 x=56)$, and although the genome constitution remains elusive, recent evidence suggests an extensive diploidization (Rousseau-Gueutin et al., 2008). The origin of strawberry traces back to the 18 th century, when natural hybridization in European horticultural gardens took place between two New World octoploid species, Fragaria virginiana Duchesne and Fragaria chiloensis (Darrow, 1966; Hancock, 1999). Both wild species are products of ancient polyploidization and natural selection (Hancock et al., 1996). The recent origin of $F$. ×ananassa, together with other characteristics of the genus such as a range of ploidy levels, the hybrid origin of several species, and the combination of discontinuous and continuous inheritance patterns, has ham-

Received for publication 5 Sept. 2008. Accepted for publication 7 Dec. 2008. Strawberry germplasm collection at the Instituto de Investigación y Formación Agraria y Pesquera (IFAPA) Centro de Churriana-Málaga is supported by grants RF02-014 and RF04-034 from the Instituto Nacional de Investigaciones Agrarias (INIA). This research was supported by the Spanish Ministry of Science and Technology (grant BIO2004-4885-C02-01) and by INIA (RTA2005-00023). D.J. Gil-Ariza was supported by a fellowship from Andalucía Regional Government (Junta de Andalucía) and I. Amaya with a contract by INIA (partly funded by European Social Funds).

${ }^{1}$ Corresponding author. E-mail: josef.sanchez@juntadeandalucía.es. pered the genetic characterization of this genus (Davis et al., 2007; Folta and Davis, 2006; Galleta and Maas, 1990).

Genetic improvement of cultivated strawberry began shortly after its origin, during the mid-18th century, but a rapid expansion occurred during the past 50 years by diverse breeding programs around the world (Hancock, 1999; Hancock et al., 1996). The strawberry is highly heterozygous and sensitive to inbreeding, being considered an outcrossing crop (Shaw, 1997). For these reasons, breeding for new strawberry cultivars requires pedigree selection, crossing of the best genotypes, and further selection. Strawberry cultivars are then vegetatively propagated through runners (or stolons) as clones. More than 500 commercial cultivars are grown worldwide (Galleta and Maas, 1990; Hancock, 1999). In Europe, $\approx 250$ strawberry cultivars are currently registered or are in the process (Community Plant Variety Office, 2008) and this number is continuously increasing. Strawberries are grown under different environmental conditions and as a result, cultivars display variable adaptations (Hancock, 1999). Each breeding program searches for cultivars adapted to specific climatic conditions. However, the sources of variability within the species are reduced to a limited number of initial cultivars. Sjulin and Dale (1987) analyzed the pedigree of 134 North American strawberry cultivars introduced between 1960 and 1985, showing that only 53 founding clones contributed to its nuclear genomic content. Nevertheless, relatively recent 
introgressions from wild octoploid species have contributed to improved diversity of the cultivated strawberry (Bringhurst and Voth, 1984; Hancock, 1999). Strawberry breeding has become an area of substantial economical importance, mainly as a result of the royalties paid to breeders for protected cultivars. Current methods for accurate detection of erroneous or illegal propagation are time-consuming and expensive because they involve the cultivation and morphological characterization of controversial cultivars for 1 to 2 years under controlled conditions. DNA fingerprinting can be implemented to assess cultivar identity and hence to protect plant breeders' rights.

A limited number of studies have used molecular markers for the analysis of population structure in polyploids. Only very recently was information on genetic diversity in $F$. virginiana and $F$. chiloensis populations provided (Carrasco et al., 2007; Hokanson et al., 2006). This is most likely the result of difficulty in the analysis of polyploid species (Röder et al., 1998). Simple sequence repeat (SSR) markers in the genus Fragaria L. have been developed from diploid species (Bassil et al., 2006a; Cipriani and Testolin, 2004; Hadonou et al., 2004; James et al., 2003; Monfort et al., 2006; Sargent et al., 2003, 2006) and octoploid species (Ashley et al., 2003; Lewers et al., 2005; Rousseau-Gueutin et al., 2008; Shimomura and Hirashima, 2006). These studies have shown a high transferability of the SSR markers among Fragaria species (see also Davis et al., 2006). Recently, the availability of sequence data derived from gene discovery programs enabled mining for SSRs in F. ×ananassa (Bassil et al., 2006b; GilAriza et al., 2006; Keniry et al., 2005; Lewers et al., 2005; Sargent et al., 2006). These markers require minimal effort to be obtained and can frequently be associated with functionally annotated genes.

The strawberry germplasm collection located at Instituto de Investigación y Formación Agraria y Pesquera (IFAPA)Centro de Churriana (Málaga, Spain) constitutes an extraordinary source of genes for breeding programs because it contains $\approx 500$ accessions, 280 of which are $F$. ×ananassa cultivars from different geographical areas and dated since 1849 ('Vicomtesse Hericart de Thury'). Available reports on the genetic characterization of cultivated strawberry have included a low number of cultivars (Arnau et al., 2002; Debnath et al., 2008; Degani et al., 2001; Graham et al., 1996; Shimomura and Hirashima, 2006). The initial objective of this study was to determine the capacity of 10 expressed sequence tag (EST)-derived SSR markers, selected by their high discriminatory power, for effective discrimination among strawberry cultivars. The genetic diversity and organization of a representative sample of the strawberry collection was evaluated. To determine the impact of plant breeding on the available diversity for further strawberry improvement, marker variability was investigated in relation to different breeding periods.

\section{Materials and Methods}

Plant material and DNA extraction. A panel of $92 \mathrm{~F}$. $\times$ ananassa accessions from different breeding programs around the world was chosen to represent the diversity within the species in the germplasm collection at IFAPA-Centro de Churriana (Sánchez-Sevilla et al., 2004) (Table 1). These include representative strawberry cultivars from diverse origins: 40 from the United States, 20 from Spain, eight from France, five from Italy, five from the United Kingdom, four from Germany, three from Holland, two from Australia, one from Belgium, one from Canada, one from Poland, one from Russia, and one old European cultivar of unknown origin. These accessions cover both a wide range of temporal and geographical origins (since the 18 th century until today) and a representative group of pedigree-related recent cultivars, which were selected to test the power of SSR markers in cultivar identification. Cultivars were organized into breeding periods based on release dates (pre-1949, 1950-1969, 1970-1980, 1981-1990, 1991-2000, post-2000) to facilitate the analysis of diversity changes (Table 1). Breeding periods were defined trying to group similar number of cultivars, although recent cultivars with Californian pedigree were in excess as a result of our objective of assessing the power of these SSR markers for cultivar identification.

Young leaf material was harvested from single plants, frozen in liquid nitrogen, and ground. Before DNA extraction, $120 \mathrm{mg}$ of tissue was washed using $1.2 \mathrm{~mL}$ washing buffer $(0.1 \mathrm{M}$ Sodium acetate, pH 5, 20 mm EDTA, 0.2 M sorbitol, $1 \mathrm{M} \mathrm{NaCl}$, 2\% PVP40, 1\% 2-mercaptoethanol). The sample was centrifuged at 3000 $g_{\mathrm{n}}$, the supernatant was discarded, and the procedure was repeated twice. Total DNA was extracted from the washed tissues using the DNeasy Plant Mini Kit (Qiagen, Valencia, CA) according to the manufacturer's instructions. DNA concentration and quality were evaluated in $0.7 \%(\mathrm{w} / \mathrm{v})$ agarose gel electrophoresis containing $0.5 \mathrm{mg} \cdot \mathrm{mL}^{-1}$ ethidium bromide using known concentrations (10 to $300 \mathrm{ng}$ ) of uncut lambda DNA (Life Technologies, Gaithersburg, MD) as standard.

POLYMERASE CHAin REACTION AMPlification AND SEPARATION OF SIMPLE SEQUENCE REPEAT MARKERS. The SSR markers used in this study were developed as previously described (Gil-Ariza et al., 2006). Amplification, separation, and visualization were carried out under the conditions described in the same reference.

Diversity ANALYSIS. A minimum of two independent polymerase chain reactions was performed for each DNA sample until two data points were available for each SSR $\times$ cultivar combination. In polyploid species, even with codominant markers as SSRs, the dosage of alleles cannot be deduced with certainty for some markers, because current technology does not allow for estimating allele dosage from observed band intensities. Consequently, allele frequency cannot be calculated directly. An alternative approach has been used to interpret polyploid banding patterns (Esselink et al., 2003). For primer pairs identifying more than two bands per accession, banding patterns observed at a particular locus were therefore recorded as a presence/absence and are referred to as "allele phenotypes." However, four primer pairs identified one or two alleles per accession and segregation was analyzed in two $F$. ×ananassa mapping populations to confirm a Mendelian "disomic" inheritance. A $\chi^{2}$ test was performed to test the goodness of fit at the 5\% level. No genotypes expected under polysomic segregation were obtained in any case and no alternative segregation fitted at $P \geq 0.05$. For ChFaM002, the segregation was analyzed in a $74 \mathrm{~F} 1$ population obtained from the cross 'Ventana' $\times$ 'Festival'. The segregation type was AA $\times \mathrm{BC}(P=0.182)$ for the expected genotypes $(50 \% \mathrm{AB}$ and $50 \%$ AC). Marker ChFaM008 was polymorphic in the same population with a segregation type $\mathrm{AC} \times \mathrm{BC}(P=0.471)$ to the expected 25\% AB, 25\% AC, 25\% BC, 25\% CC segregation. ChFaM021 was polymorphic in the two mapping populations analyzed. The second consisted of a 95 progeny from a cross 
Table 1. List of Fragaria $\times$ ananassa germplasm, organized into breeding periods based on release dates, used to evaluate the genetic diversity. ${ }^{\mathrm{z}}$

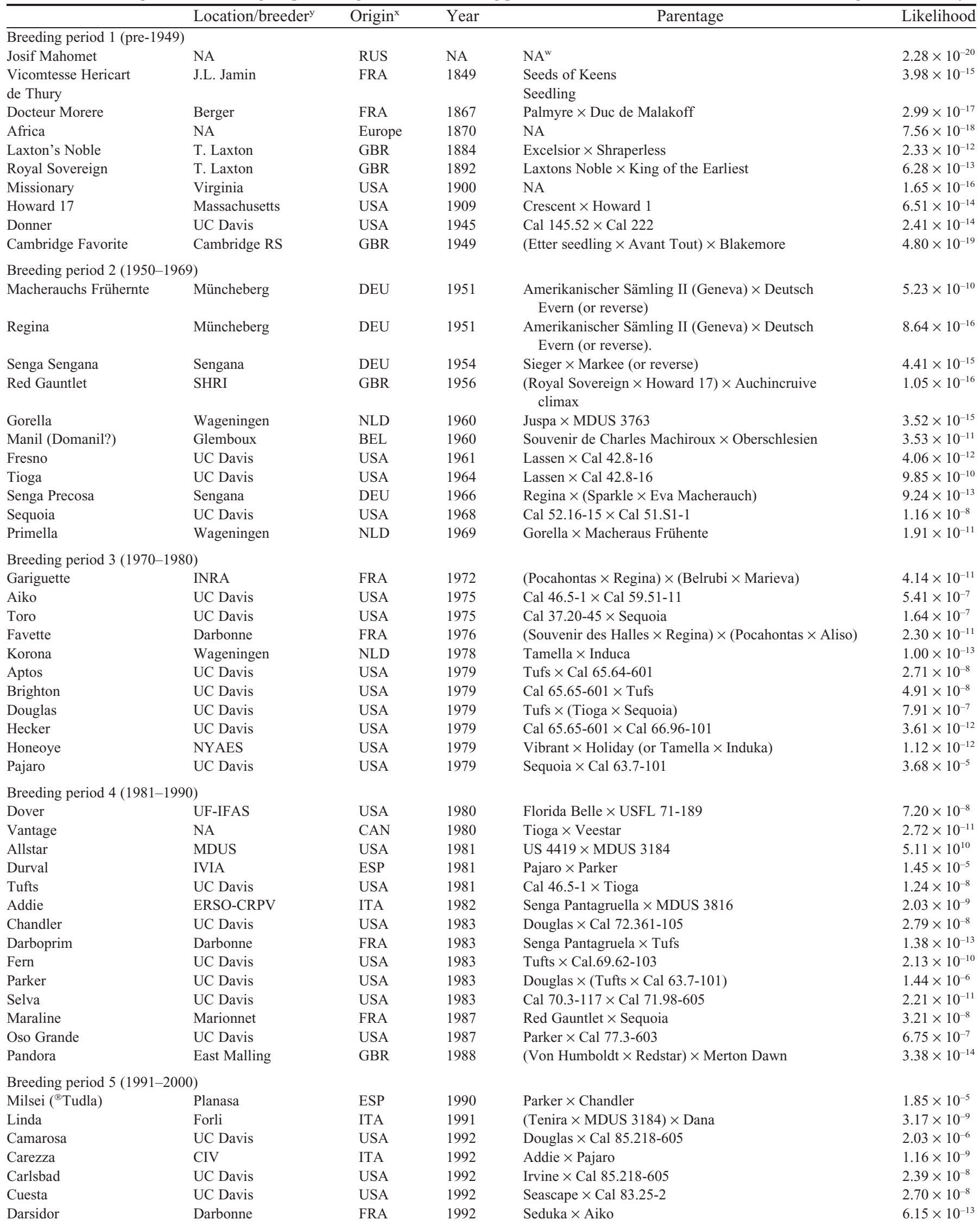


Table 1. Continued.

\begin{tabular}{|c|c|c|c|c|c|}
\hline & Location/breeder ${ }^{\mathrm{y}}$ & Origin $^{x}$ & Year & Parentage & Likelihood \\
\hline Laguna & UC Davis & USA & 1992 & Irvine $\times$ Cal 85.92-602 & $1.29 \times 10^{-6}$ \\
\hline Vilanova & IVIA & ESP & 1992 & Aiko $\times$ Chandler & $2.99 \times 10^{-8}$ \\
\hline Cartdos & Planasa & ESP & 1993 & NA & $4.47 \times 10^{-7}$ \\
\hline Cartuno & Planasa & ESP & 1993 & Planasa $86-184 \times$ Planasa 86-175 & $7.92 \times 10^{-8}$ \\
\hline Redlands Hope & Redlands & AUS & 1993 & Parker $\times$ Redlands Promise & $4.12 \times 10^{-7}$ \\
\hline Redlands Star & Redlands & AUS & 1993 & NA & $1.87 \times 10^{-9}$ \\
\hline Teodora & Forli & ITA & 1993 & {$[$ Toro $\times($ Belrubi $\times$ Titan $)] \times$ Douglas } & $9.23 \times 10^{-12}$ \\
\hline Arena & Planasa & ESP & 1995 & Planasa $85-20 \times$ Planasa $86-175$ & $7.66 \times 10^{-8}$ \\
\hline Medina & IFAPA-INIA-IVIA & ESP & 1995 & Z $45 \times$ Parker & $2.19 \times 10^{-7}$ \\
\hline Missionary Hybrid & Louisiana & USA & 1995 & $F$. virginiana $\times$ Missionary & $3.68 \times 10^{-24}$ \\
\hline Darselect & Darbonne & FRA & 1996 & Elsanta $\times$ Parker & $4.32 \times 10^{-11}$ \\
\hline Sel. $232-2$ & IFAPA-INIA-IVIA & ESP & 1996 & $4-43 \times$ Vilanova & $7.29 \times 10^{-8}$ \\
\hline Gaviota & UC Davis & USA & 1996 & Cal 87.112-6 × Cal 88.270-1 & $6.50 \times 10^{-7}$ \\
\hline Marina & IFAPA-INIA-IVIA & ESP & 1997 & Cartuno $\times$ Camarosa & $2.68 \times 10^{-6}$ \\
\hline Plasirfre $\left({ }^{\circledR}\right.$ Tudnew $)$ & Planasa & ESP & 1997 & Planasa 85-20 × Planasa 86-061 & $9.02 \times 10^{-9}$ \\
\hline Ventana & UC Davis & USA & 1997 & Cal 93.170-606 × Cal 92.35-601 & $5.77 \times 10^{-7}$ \\
\hline Aguedilla & IFAPA-INIA-IVIA & ESP & 1998 & Camarosa $\times 67.35$ & $9.23 \times 10^{-6}$ \\
\hline Carisma & IFAPA-INIA-IVIA & ESP & 1998 & Oso Grande $\times$ Vilanova & $3.69 \times 10^{-7}$ \\
\hline Pelican & MDUS & USA & 1998 & FL $82-1556 \mathrm{P} \times$ LA 8311 & $2.68 \times 10^{-10}$ \\
\hline Andana & IFAPA-INIA-IVIA & ESP & 1999 & $($ Garriguete $\times$ Parker $) \times($ Vilanova $\times$ Ribera $)$ & $3.66 \times 10^{-8}$ \\
\hline \multicolumn{6}{|c|}{ Breeding period 6 (post-2000) } \\
\hline Plarionfre ( ${ }^{\circledR}$ Chiflón) & Planasa & ESP & 2000 & Sel. $92-44 \times$ Sel. $86-032$ & $1.21 \times 10^{-7}$ \\
\hline Festival & UF-IFAS & USA & 2000 & Rosalinda $\times$ Oso Grande & $6.58 \times 10^{-8}$ \\
\hline Naiad & CIV & ITA & 2001 & NA & $1.11 \times 10^{-6}$ \\
\hline Witney & VPP & USA & 2002 & Sel.89530506 × Sel.89542504 & $1.69 \times 10^{-9}$ \\
\hline Camino Real & UC Davis & USA & 2003 & Cal $89.2307 \times$ Cal 90.2533 & $2.11 \times 10^{-6}$ \\
\hline Sabrosa $\left({ }^{\circledR}\right.$ Candonga $)$ & Planasa & ESP & 2003 & Sel. $9238 \times$ Sel. 86032 & $2.75 \times 10^{-5}$ \\
\hline Plahuelfre & Planasa & ESP & 2003 & Sel. $9244 \times$ Sel. 86032 & $3.27 \times 10^{-6}$ \\
\hline Carmela & Planasa & ESP & 2004 & Sel. $86032 \times$ Sel. 9261 & $3.86 \times 10^{-7}$ \\
\hline Cisco & FNM & ESP & 2004 & NA & $1.07 \times 10^{-6}$ \\
\hline Commitment & Berry Genetics & USA & 2004 & NA & $7.09 \times 10^{-8}$ \\
\hline Endurance & $\begin{array}{l}\text { Berry Genetics, } \\
\text { Plant Science }\end{array}$ & USA & 2004 & NA & $9.10 \times 10^{-9}$ \\
\hline Galante & California Giant & USA & 2004 & Sel. C1 × Sel. NWFV & $4.37 \times 10^{-10}$ \\
\hline Galexia & California Giant & USA & 2004 & NA & $9.77 \times 10^{-8}$ \\
\hline Gloria & California Giant & USA & 2004 & Sel. A41 × Seascape & $1.92 \times 10^{-8}$ \\
\hline Honor & Berry Genetics & USA & 2004 & Camarosa $\times$ PS-1269 & $1.58 \times 10^{-7}$ \\
\hline Macarena & Planasa & ESP & 2004 & Sel. $88-033 \times$ Sel. 9150 & $5.35 \times 10^{-7}$ \\
\hline Patience & Berry Genetics & USA & 2004 & Anaheim × PS-592 & $2.80 \times 10^{-7}$ \\
\hline Pedrone & FNM & ESP & 2004 & NA & $2.82 \times 10^{-6}$ \\
\hline Salut & Skierniewice & POL & 2004 & Selva $\times$ Ducat & $8.54 \times 10^{-12}$ \\
\hline
\end{tabular}

${ }^{\mathrm{z}}$ Cultivar name, location or breeder, country of origin, year of release, parentage, and probability of obtaining a particular allele phenotype with the 10 loci (likelihood) are provided.

${ }^{y} \mathrm{NA}=$ data not available; Berger $=$ French breeder, first name unknown; UC Davis $=$ University of California, Davis; Cambridge RS $=$ Cambridge Research Station, Cambridge, UK; Münchcheberg = Kaiser-Wilhelm-Institut für Züchtungsforschung, Münchcheberg, Germany; Sengana = Sengana GmbH, Ahrensburg, Germany; SHRI = Scottish Horticultural Research Institute, Dundee, UK; Wageningen = Institute of Horticultural Plant Breeding, Wageningen, The Netherlands; Gembloux = Center de Recherches Agronomiques, Gembloux, Belgium; INRA = Institut Nationale de la Recherche Agronomique, Paris; Darbonne = Darbonne, Le Barp, France; NYAES = Cornell University, New York Agricultural Experiment Station, Geneva, NY; UF-IFAS = University of Florida, Institute of Food and Agricultural Sciences, Winauma; MDUS = U.S. Department of Agriculture, Beltsville, MD; IVIA = Instituto Valenciano de Investigaciones Agrarias, Moncada, Spain; ERSO-CRPV = L'Ente Regionale Sviluppo Ortofrutticolo-Centro Regionale Produzioni Vegetali, Ancona, Italy; Marionnet = Marionnet, Soings-en-Sologne, France; East Malling = East Malling Research. East Malling, UK; Planasa = Plantas de Navarra, Cintruenigo, Spain; Forli = Istituto Sperimentale per la Frutticoltura, Sezione di Forli, Italy; CIV = Consorzio Italiano Vivaisti, Ferrara, Italy; Redlands = Redlands Horticultural Research Station, Cleveland, Australia; IFAPA-INIA-IVIA = Instituto de Investigación y Formación Agraria (Sevilla, Spain)-Instituto Nacional de Investigación y Tecnología Agraria y Alimentaria (Madrid, Spain)-IVIA; VPP = V.P.P. Corp., Oakland, CA; FNM = Fresa Nuevos Materiales, Huelva, Spain; Berry Genetics = Berry Genetics, East Lansing, MI; Plant Science = Plant Science, Watsonville, CA; California Giant = California Giant, Watsonville, CA; Skierniewice $=$ Skierniewice Experimental Station, Warsaw Agricultural University, Warsaw, Poland.

${ }^{x}$ RUS = Russia $;$ FRA = France $;$ GBR $=$ United Kingdom; USA = United States; DEU = Germany; NLD = The Netherlands; BEL = Belgium; CAN $=$ Canada $; \mathrm{ESP}=$ Spain; ITA $=$ Italy; AUS = Australia; POL $=$ Poland.

${ }^{w} \mathrm{NA}=$ data not available. 
between two breeding lines: $232-2 \times 1391-1$. Segregation types for each population were $\mathrm{CC} \times \mathrm{CB}$ and $\mathrm{AC} \times \mathrm{CC}$ and both fitted the expected genotypes, $50 \% \mathrm{CC}$ and $50 \% \mathrm{CB}$ or $\mathrm{AC}$, respectively ( $P=0.838$ and 0.669 , respectively). Marker ChFaM005 was not polymorphic in either population. For these diploid markers, gene diversity was calculated according to the formula of Nei (1973): $H=1-\sum p_{i j}{ }^{2}$, where $p_{i j}$ is the frequency of the $j$ th allele for the $i$ th locus. According to Anderson et al. (1993), we referred to gene diversity as the polymorphic information content (PIC).

An equivalent estimate of gene diversity, using allelic phenotype data instead of genotype data, is referred to as "power of discrimination" ( $\left.P D=1-\sum g_{k}^{2}\right)$, where $g_{k}$ is the frequency of the $k$ th allelic phenotype obtained with the combination of bands present at a particular locus (Kloosterman et al., 1993). This statistic measures the ability of a marker to discriminate between two cultivars. $P D$ values were used to calculate the confusion probability $\left[\mathrm{C}=\prod\left(1-P D_{i}\right)\right.$, where $P D_{i}$ is the $P D$ value of the $i$ th locus], which estimates the probability that any two cultivars had identical SSR genotypes by chance alone considering all loci (Tessier et al., 1999).

Analysis of population STRUCTURE. To assess the structure of genetic diversity among cultivars, we used three complementary approaches: graphic clustering from similarity data, a Bayesian model-based clustering method, and an analysis of molecular variance (AMOVA).

The genetic similarity (GS) between cultivars was calculated with presence/absence data for each cultivar according to Nei and Li (1979) where GS $=2 n_{X Y} /\left(n_{X}+n_{Y}\right)$, in which $n_{X}$ and $n_{\mathrm{Y}}$ are the number of fragments present in cultivars $\mathrm{X}$ and $\mathrm{Y}$, respectively, whereas $n_{\mathrm{XY}}$ is the number of fragments shared by the two cultivars. This estimator was used for cluster analysis using unweighted pair group method with arithmetic mean (UPGMA) with the package Phylip 3.65 (Felsenstein, 1989). Bootstrap analysis was performed with 5000 replicates. We also used the Bayesian model-based clustering method implemented in the software STRUCTURE 2.2 (Pritchard et al., 2000). This method assigns each genotype to a number of groups on the basis of the information given by molecular markers. We used the basic admixture model with unlinked loci and uncorrelated allele frequencies with the assumed number of populations $(\mathrm{K})$ varying from one to 10 and 10 replicate runs per $\mathrm{K}$ value. There are different statistical methods that estimate the number of clusters, or populations, that best adjusts to the data. Thus, the probability that the examined cultivars (genotypes, X) are grouped in the analyzed populations was calculated from $\operatorname{Ln}[P(\mathrm{X} / \mathrm{K})]$. For each assumed population structure, we discarded the first $10^{4}$ iterations as a burn-in period and used the following $10^{5}$ iterations to produce the results of the group membership probabilities for individual genotypes. The run showing the highest posterior probability of data was considered for each $\mathrm{K}$ value. For diploid markers, we introduced the data as standard codominant markers; for the rest (polyploid markers), we introduced the data as dominant markers according to the new version of the software (Falush et al., 2007).

The genetic structure of strawberry cultivars was further investigated by an AMOVA using the software ARLEQUIN 3.11 (Excoffier et al., 2005). The AMOVA analysis was performed separately using presence/absence data for polyploid markers and allele frequency for diploid markers (those markers that showed only one or two alleles in each cultivar).
The significance of the partitioning of genetic variance among groups was tested. Groups were defined according to clusters obtained by the analysis using STRUCTURE 2.2 and also for the six different breeding periods.

\section{Results}

Simple SEQUenCe REPEAT MARKER DIVERSITY. A panel of 92 $F$. Xananassa accessions was genotyped with 10 polymorphic EST-SSRs allowing the identification of several alleles per locus (Table 2). Four EST-SSRs (ChFaM002, ChFaM005, ChFaM008, and ChFaM021) identified one or two alleles per accession, whereas the other six EST-SSRs identified between one and eight bands as previously reported with a reduced set of cultivars (Gil-Ariza et al., 2006). These results are consistent with allele amplification on single (one to two bands) or duplicated/homoeologous (greater than two bands) loci in the octoploid genome of $F$. ×ananassa. This may also reflect the mixed behavior (disomic-polysomic) shown by other authors in F. ×ananassa (Lerceteau-Köhler et al., 2003) and in $F$. virginiana (Ashley et al., 2003). To investigate the genetic nature of the markers used in our study, we analyzed the segregation of primer pairs ChFaM002, ChFaM005, ChFaM008, and ChFaM021 in two $F$. ×ananassa mapping populations. Three of them showed Mendelian segregation (disomic inheritance), being indeed diploid markers (as shown in "Material and Methods"). ChFaM005 primers generated a single DNA band, thus being homozygous in both segregating populations.

A total of 95 alleles were identified with an average of 9.5 alleles per locus (Table 2). Thirty-eight alleles (40\%) were present in a small proportion of cultivars (less than $10 \%$ of the cultivars) and three alleles (3\%) were present in most of them (greater than 90\%). None of the alleles was present in every cultivar. Cultivars Africa, Cambridge Favorite, Docteur Morere, Donner, Missionary Hybrid, and Teodora presented one exclusive allele each (ChFaM029.162, ChFaM023.180, ChFaM014.179, ChFaM002.201, ChFaM008.155, and ChFaM021.233, respectively). Allelic composition of 92 strawberry accessions analyzed is included in Supplementary Table S1.

Gene diversity for diploid markers ranged from 0.52 to 0.68 $($ mean $=0.62)($ Table 2$)$. The PD for the different loci ranged from 0.68 for ChFaM005 to 0.98 for $\mathrm{ChFaM023}($ mean $=0.88)$ (Table 2). Using the $10 \mathrm{PD}$ values, we calculated the total probability of confusion to be $1.46 \times 10^{-11}$. The likelihood of obtaining a particular allelic phenotype within strawberry cultivars ranged from $1.45 \times 10^{-5}$ to $3.68 \times 10^{-24}$ (Table 1 ). Therefore, the selected EST-SSRs allowed unambiguous discrimination of all the cultivated strawberry accessions analyzed.

GENETIC RELATIONSHIP AMONG STRAWBERRY CULTIVARS. Nei and $\mathrm{Li}$ genetic similarity coefficients ranged from 0.21 ('Primella' versus 'Aguedilla') to 0.98 ('Parker' versus 'Aiko') with a mean value of $0.56( \pm 0.12)$ and a mode value of 0.67. Average similarity within different breeding periods increased with time ( 0.45 to 0.66$)$ (Table 3$)$. The high level of coancestry among strawberry cultivars, and among modern cultivars in particular, is reflected in the coefficients of similarity with values over $70 \%$ for many of the accessions. Among the modern cultivars with Californian pedigree, the 
Table 2. Motif, position within the expressed sequence tag (EST), allele size range (bp), and putative function based on homology to protein databases for 10 EST-SSR loci. ${ }^{\mathrm{z}}$

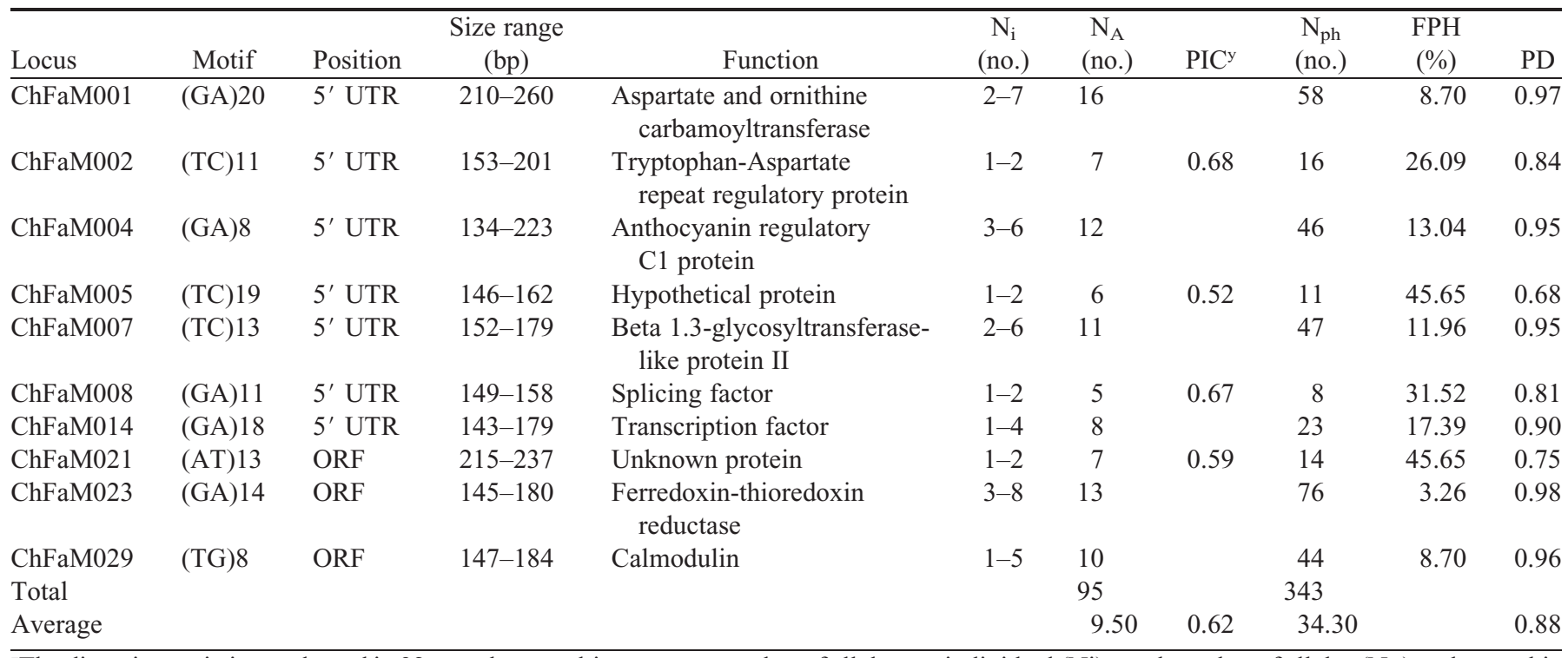

${ }^{\mathrm{z}}$ The diversity statistics evaluated in 92 strawberry cultivars were: number of alleles per individual (Ni), total number of alleles ( $\left.\mathrm{N}_{\mathrm{A}}\right)$, polymorphic information content (PIC), number of unique allelic phenotypes $\left(\mathrm{N}_{\mathrm{ph}}\right)$, frequency of the most prevalent allelic phenotype (FPH), and power of discrimination (PD).

${ }^{y}$ Determined only for primers pairs that amplified up two bands per cultivar.

$\mathrm{SSR}=$ simple sequence repeat.

Table 3. Number of alleles, proportion of total alleles, and average Nei and Li genetic similarity (GS) within the six different breeding periods and three theoretical groups (red, blue, green) based on the software STRUCTURE 2.2 (Pritchard et al., 2000) determined from the analysis of 10 EST-SSR markers in 92 strawberry cultivars.

\begin{tabular}{lccccccccc}
\hline Groups & Pre-1949 & $1950-1969$ & $1970-1979$ & $1980-1989$ & $1990-1999$ & Post-2000 & Red & Blue & Green \\
\hline Cultivars (no.) & 10 & 11 & 11 & 14 & 27 & 19 & 26 & 22 & 44 \\
Alleles (no.) & 86 & 75 & 68 & 70 & 72 & 56 & 94 & 70 & 66 \\
$\begin{array}{l}\text { Proportion } \\
\quad \text { of total alleles (\%) }\end{array}$ & 93.48 & 78.94 & 73.68 & 71.58 & 85.26 & 60.00 & 98.85 & 73.68 & 69.47 \\
$\begin{array}{l}\text { Mean GS } \\
\text { Range of variation }\end{array}$ & 0.75 & 0.47 & 0.54 & 0.58 & 0.63 & 0.66 & 0.45 & 0.60 & 0.70 \\
\end{tabular}

EST-SSR $=$ expressed sequence tag-simple sequence repeat.

similarity ranged from 0.37 ('Tioga' versus 'Maraline') to 0.98 ('Parker' versus 'Aiko') with a mean value of 0.70 (Table 3). Graphic clustering using UPGMA arranged strawberry cultivars into several small groups, which appear to be related based on pedigrees (Fig. 1A). Modern cultivars with Californian pedigree were distributed at the top, had short branches, and similarities over $73 \%$. The most recent cultivars obtained by the University of California, Davis or Spanish breeders, having a similar pedigree, high coancestry, and analogous climatic adaptation, were clustered at the upper part of the dendrogram, whereas old European cultivars appear at the bottom. The two most distant cultivars, Josif Mahomet and Missionary Hybrid, were very different from the rest (with a similarity to the next group of only $35 \%$ ), supporting the idea that they were introgressed with wild germplasm. In contrast to the majority of the groups, there was strong support for this cluster with a bootstrap value of $100 \%$. The cultivars in the middle of the tree include both intermediate old cultivars with mixed pedigree and other cultivars with European or American pedigree. In general, genetically related cultivars (paren- tal lines with their descendants) clustered together in the tree. As an example, 'Parker' clustered together with 'Douglas', its maternal parent, and with 'Durval' and 'Tudla', two direct descendants.

Population structure. We next investigated the population structure in the 92 accessions using STRUCTURE 2.2. This analysis estimates the most likely number of potential clusters $(\mathrm{K})$ by calculating the log probability of data for each value of $\mathrm{K}$. With the 92 cultivars selected in this study, the most probable number of populations was three. The three populations are represented with different colors in Figure 1B. The green population contains 44 accessions with 'Camarosa' representing this group because its genetic background contains the maximum proportion derived from this population. It corresponds to cultivars with Californian pedigree that are well adapted to the Mediterranean/Californian environment and with the majority belonging to the three most recent breeding periods (released after 1980). The red population is composed of 26 old accessions (most of them released before 1969) from either European or American origin with 'Missionary Hybrid' 


\section{B}

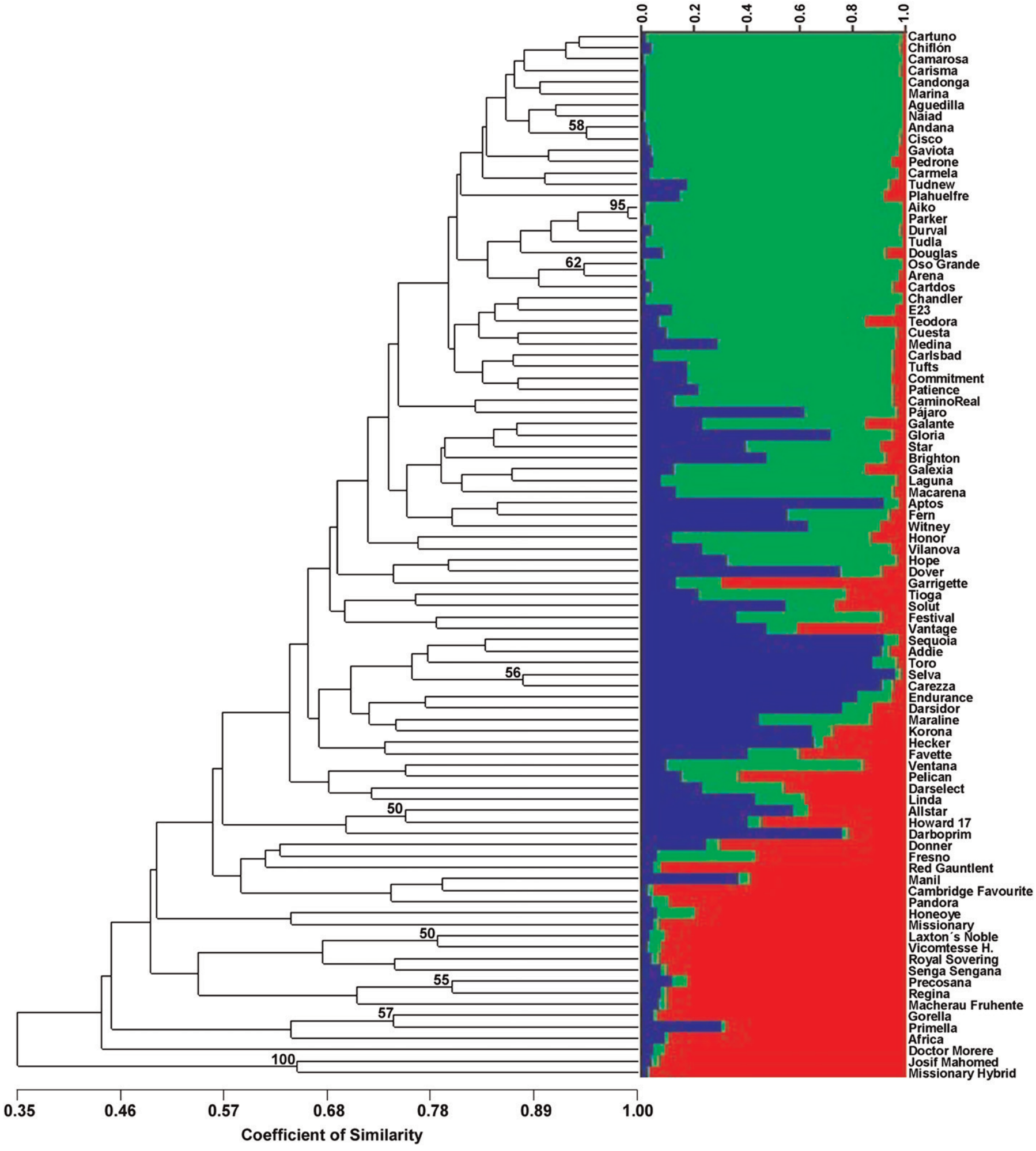

Fig. 1. Genetic relationships among the 92 strawberry cultivars. (A) Dendrogram based on Nei and Li similarity matrix and unweighted pair group method with arithmetic mean cluster analysis. Bootstrap values higher than $50 \%$ are placed on branches. (B) Group probabilities obtained for K $=3$ by STRUCTURE 2.2 (Pritchard et al., 2000). Each bar represents the genetic background of a cultivar according to the proportion derived from each of the three different subpopulations.

and 'Cambridge Favorite' as representatives of this group. The blue population, with 'Selva' as an example of this group, comprised 22 cultivars from different breeding periods and with admixture with the other two populations.
Changes in molecular variance. Based on AMOVA, significant variance differences were found among the groups of strawberry cultivars established here. Overall, the results were very similar using both diploid and polyploid marker data 
(Table 4). The highest percentage of allele variability was caused by differences among cultivars $(84.78 \%$ and $83.77 \%$ for diploid and polyploid markers, respectively). Only $15.22 \%$ or $16.23 \%$ of the variation (depending on marker type) was caused by differences among theoretical STRUCTURE 2.2 groups. Breeding periods had a lower effect on the variation $(8.70 \%$ and $7.01 \%$ for diploid and polyploid markers, respectively). The overall $\mathrm{F}_{\mathrm{ST}}$ values were 0.15 and 0.16 with diploid and polyploid markers, respectively, suggesting a limited but significant differentiation between subpopulations and the absence of clearly defined clusters. Genetic differentiation was higher $(0.17 \%)$ in the green group (California pedigree) than in blue and red groups with ancient cultivars being the least differentiated with an $\mathrm{F}_{\mathrm{ST}}$ value of only 0.15 (Table 4). The most recent breeding groups (1991-2000 and post-2000) had a higher $\mathrm{F}_{\mathrm{ST}}$ value $(0.077$ and 0.082 , respectively) than previous breeding periods $(0.049$ to 0.072$)$ (Table 4$)$.

\section{Discussion}

The use of 10 EST-SSRs loci, detecting 95 alleles, was sufficient to discriminate among all the representative strawberry genotypes selected from our germplasm collection and to analyze $F$. ×ananassa diversity. The number of alleles detected per primer pair ranged from five to 16 with a mean value of 9.5 (Table 2). This value is similar to 7.3 and 16.1 described for other EST-SSR markers in F. ×ananassa (Bassil et al., 2006b; Keniry et al., 2005). A slightly lower number of alleles (6.6 bands per primer pair) was reported with genomic SSR markers (Hokanson et al., 2006), but in this case, only five genotypes were tested. A high number of alleles per locus was also shown for genomic SSR markers analyzed in wild octoploid populations: 21.6 in different octoploid species of America (Hokanson et al., 2006) and 13.5 alleles per locus in F. virginiana (Ashley et al., 2003). However, the number of alleles reported in diploid Fragaria species was always lower: 3.9 (James et al., 2003), 4.9
(Hadonou et al., 2004; Sargent et al., 2003, 2004), and 5.3 (Monfort et al., 2006) alleles per locus. The higher number of alleles detected in octoploid strawberries likely arises from its highly heterozygous and polyploid nature (Galleta and Maas, 1990). When compared with other polyploid species such as wheat [Triticum turgidum L. ssp. durum (Desf.) Husn.] (5.7 alleles; Maccaferri et al., 2003) and sugarcane (Saccharum L. spp.) (6.4 alleles; Pinto et al., 2004), the numbers found in strawberry were also higher.

The probabilities of obtaining a particular allelic phenotype using these 10 loci ranged from as low as $3.68 \times 10^{-24}$ for 'Missionary Hybrid' to $1.45 \times 10^{-5}$ for 'Durval' (Table 1). This high discrimination occurred even between genotypes such as 'Andana', 'Carisma', 'Camarosa', 'Marina', 'Chandler', 'Tudla', 'Durval', 'Oso Grande', and 'Parker', all of them with 'Douglas' in their pedigree (Table 1). Calculated PIC based on allelic frequencies varied from 0.52 to 0.68 for the four diploid markers. Keniry et al. (2005) obtained PIC values ranging from 0.53 to 0.84 for EST-SSR markers, although these values may be overestimated because the authors used 14 markers that detected more than two alleles per accession. Previous studies have shown that SSRs located in the 3' UTR of the EST present greater levels of polymorphisms than those in the $5^{\prime}$ UTR or in the open reading frame (Gupta et al., 2003; Thiel et al., 2003; Yong et al., 2004). The 10 EST-derived markers evaluated in this study were located in the 5' UTR or in the coding region; nevertheless, they showed a high level of polymorphism. The high PD values and a combined probability of confusion lower than one in $10^{11}$ suggest that these 10 SSR markers could be highly useful for strawberry identification.

The high discriminatory power of this set of makers, even between closely related cultivars, has also allowed the evaluation of the genetic diversity and population structure of this strawberry collection. Four of the SSR markers showed one or two alleles per cultivar and disomic inheritance, allowing classical analysis of allele frequencies. For the rest of markers,

Table 4. Analysis of molecular variance for 92 strawberry cultivars using 95 EST-SSR bands in three theoretical groups (red, blue, green) obtained with STRUCTURE 2.2 software (Pritchard et al., 2000) in the six different breeding periods. ${ }^{\mathrm{z}}$

\begin{tabular}{lcccc}
\hline Source of variation & $\begin{array}{c}\text { df [diploid } \\
\text { (polyploid) } \\
\text { markers] }\end{array}$ & $\begin{array}{c}\text { Sum of squares } \\
\text { [diploid (polyploid) } \\
\text { markers] }\end{array}$ & $\begin{array}{c}\text { Variance components } \\
\text { [diploid (polyploid) } \\
\text { markers] }\end{array}$ & $\begin{array}{c}\text { Percentage of } \\
\text { variation [diploid } \\
\text { (polyploid) markers] }\end{array}$ \\
\hline Among theoretical groups & 2 & $25.555(114.946)$ & $0.1999(1.6739)^{* * *}$ & $15.22(16.23)$ \\
Within theoretical groups & $181(89)$ & $201.581(768.848)$ & $1.1137(8.6387)^{* * *}$ & $84.78(83.77)$ \\
Among breeding periods & 5 & $22.076(97.021)$ & $0.1098(0.6901)^{* * *}$ & $8.70(7.01)$ \\
Within breeding periods & $178(86)$ & $205.060(786.773)$ & $1.1520(9.1485)^{* * *}$ & $91.30(92.99)$ \\
Total & $183(91)$ & $227.136(883.793)$ & &
\end{tabular}

Genetic differentiation $\left(\mathrm{F}_{\mathrm{ST}}\right)$ in theoretical groups (red, blue, green) obtained with STRUCTURE 2.2 in the six different breeding periods. Analysis was performed with diploid and polyploid markers (in parentheses) separately.

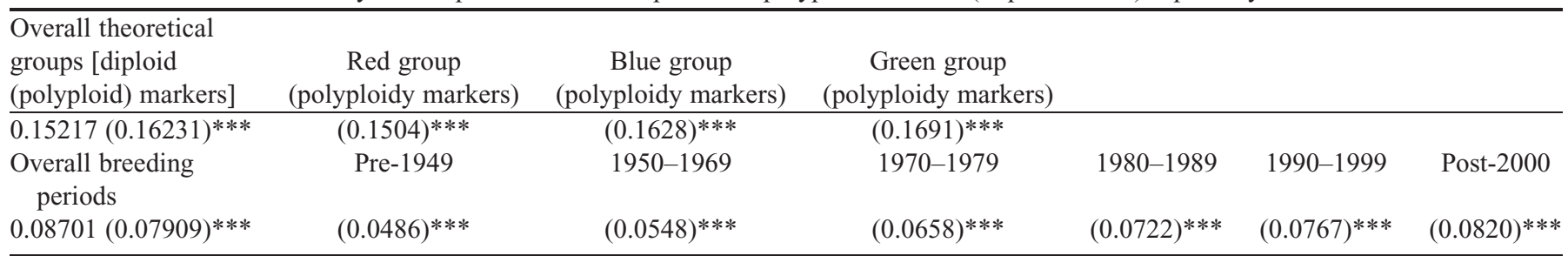

${ }^{\mathrm{z}}$ Analysis was performed with diploid and polyploid markers (in parentheses) separately.

*** Significant at $P<0.001$.

EST-SSR $=$ expressed sequence tag-simple sequence repeat. 
alternative analyses were used. Interestingly, both approaches gave very similar estimates of genetic diversity, revealing evidence of moderate population structure among the 92 strawberry cultivars. The cluster analysis is a distance-based method using the proportion of shared alleles to calculate distances. This method is advantageous because it does not overestimate the relatedness between individuals because band absences are excluded from analyses and there are no assumptions of Hardy-Weinberg equilibrium. STRUCTURE 2.2 uses a Bayesian clustering approach that probabilistically assigns individuals to different groups based on their genotypes. For organisms with ploidy greater than two, genotypic ambiguity may exist even if all alleles are codominant. STRUCTURE 2.2 implements an algorithm that generates appropriate genotypes given both this ambiguity and (optionally) the ambiguity caused by recessive nulls, allowing dominant (polyploid) markers to be used (Falush et al., 2007). The cluster analysis did not separate the cultivars in apparent major groups but arranged them in function of their ancestry, from recent cultivars with Californian pedigree and adapted to Mediterranean environments (joined with coefficients of similarity higher than $78 \%$ ) to the oldest ones with lower similarities among them (Fig. 1A). STRUCTURE 2.2 distinguished three potential populations (Fig. 1B). Two of them, the "green" and "red" populations, were separated in the dendrogram (Fig. 1A). The "green" group contained most of the cultivars obtained after 1980, which are the result of a very specific agroclimatic adaptation and are more inbred with the number of alleles reduced from 95 to 66 (more than $69 \%$ reduction; Table 3 ). The "red" group represented the oldest and more diverse cultivars (mean GS $=0.44$ ) with a number of them generated from backcrosses with wild ancestors. In contrast to the other two groups, the "blue" group contained substantial intermixing of genetic background. Cultivars assigned to this group appeared in the middle of the dendrogram in the cluster analysis (Fig. 1A). They may represent alternative genetic combinations adapted to other environmental clues such as day neutrality (because most day-neutral selections were in this group).

AMOVA partitions observed variation within and among population components using genetic distances. The method was originally designed to analyze codominant data, but polyploid data can be treated as molecular haplotypes. This analysis further demonstrated that most of the diversity of $F$. xananassa cultivars was attributed to differences among genotypes. Nevertheless, $15.22 \%$ (or $16.23 \%$ with polyploid markers) of the variation was attributed to differences among theoretical STRUCTURE 2.2 populations. The effect of breeding dates on the variation was even lower $(8.70 \%$ or $7.01 \%$ depending of the SSR markers; Table 4). In wild $F$. chiloensis ssp. chiloensis accessions, most genetic variation was also found within populations, whereas the variance between the two botanical forms, F. chiloensis ssp. chiloensis forma patagonica Staudt and F. chiloensis ssp. chiloensis forma chiloensis Staudt, cultivated by aboriginal people of Chile, was just 14.9\% (Carrasco et al., 2007). After two centuries of strawberry breeding, the collection of cultivars shows comparable genetic variation or structure to one of its wild ancestors. The overall $\mathrm{F}_{\mathrm{ST}}$ value was $\approx 0.16$ for $F$. $\times$ ananassa indicating a slight degree of differentiation in the collection. Specific $\mathrm{F}_{\mathrm{ST}}$ estimates for each population indicate that modern Californian/Mediterranean cultivars are slightly more differentiated $(\approx 0.17)$ than the other two groups (with 0.16 and 0.15 for the "blue" and "red" populations, respectively; Table 4), indicating a reduction of genetic diversity in these cultivars, most probably as a consequence of the recurrent selection to this agroclimatic environment. From a temporal point of view, there was a clear decrease in the number of alleles and an increase of genetic similarity in more recent breeding periods (Table 3 ). However, the low genetic differentiation $\left(\mathrm{F}_{\mathrm{ST}}\right)$ in these groups $(\approx 8 \%$; Table 4$)$ indicates that breeding periods did not play a major role in the genetic structure.

The EST-SSR markers used in the present study will allow accurate cultivar certification in strawberry during the propagation in nurseries and also at different key points in the commercialization process. Increasing the number of markers, expanding the analysis to all the germplasm collection, and also adding morphological data will allow the finding of marker trait associations by LD mapping (Lynch and Walsh, 1998). Overall, the results presented here demonstrate the usefulness of SSRs for strawberry germplasm characterization. In addition, the exploitation of EST-derived SSRs, because they reveal variation in transcribed regions of the strawberry genome, has the advantage of dealing with markers more stable than highly variable genomic SSRs. This study suggests that 200 years of breeding has produced a small reduction in the genetic diversity of cultivated strawberry. Certainly, the use of clones of wild species in the development of cultivars released since 1960 in North American public breeding programs has contributed to the maintenance of the genetic diversity (Sjulin and Dale, 1987) and may explain how plant breeders have been able to continue to make significant improvements in strawberry breeding. In addition, this study provides useful information on cultivars that constitute a potential source of variability for the species.

\section{Literature Cited}

Anderson, J.A., G.A. Churchill, J.E. Autrique, M.E. Sorrells, and S.D. Tanksley. 1993. Optimizing parental selection for genetic linkage maps. Genome 36:181-186.

Arnau, G., J. Lallemand, and M. Bourgoin. 2002. Fast and reliable strawberry cultivar identification using inter simple sequence repeat (ISSR) amplification. Euphytica 129:69-79.

Ashley, M.V., J.A. Wilk, S.M.N. Styan, K.J. Craft, K.L. Jones, K.A. Fedkheim, K.S. Lewers, and T.L. Ashman. 2003. High variability and disomic segregation of microsatellites in octoploid Fragaria virginiana Mill. (Rosaceae). Theor. Appl. Genet. 107:1201 1207.

Bassil, N.V., M. Gunn, K. Folta, and K. Lewers. 2006b. Microsatellite markers for Fragaria from 'Strawberry Festival' expressed sequence tags. Mol. Ecol. Notes 6:473-476.

Bassil, N.V., W. Njuguna, and J.P. Slovin. 2006a. EST-SSR markers from Fragaria vesca L. cv. Yellow Wonder. Mol. Ecol. Notes 6:806809.

Bringhurst, R.S. and V. Voth. 1984. Breeding octoploid strawberries. Iowa State J. Res. 58:371-381.

Carrasco, B., M. Garces, P. Rojas, G. Saud, R. Herrera, J.B. Retamales, and P.D.S. Caligari. 2007. The chilean strawberry [Fragaria chiloensis (L.) Duch.]: Genetic diversity and structure. J. Amer. Soc. Hort. Sci. 132:501-506.

Cipriani, G. and R. Testolin. 2004. Isolation and characterization of microsatellite loci in Fragaria.. Mol. Ecol. Notes 4:366-368.

Community Plant Variety Office. 2008. Applications and titles in force. Botanical taxon: Fragaria Xananassa. 8 Jan. 2008. <http:// 
www.cpvoextranet.cpvo.europa.eu/WD120AWP/WD120Awp.exe/ CONNECT/ClientExtranet>.

Darrow, G.M. 1966. The strawberry. Holt, Rinehart and Winston, New York, NY

Davis, T.M., B. Denoyes-Rothan, and E. Lerceteau-Köhler. 2007. Strawberry, p. 189-205. In. Kole, C. (ed.). Genome mapping and molecular breeding in plants. Vol. 4. Springer-Verlag, Berlin/ Heidelberg, Germany.

Davis, T.M., L.M. DiMeglio, R. Yang, S.M.N. Styan, and K.S. Lewers. 2006. Assessment of SSR marker transfer from the cultivated strawberry to diploid strawberry species: Functionality, linkage group assignment, and use in diversity analysis. J. Amer. Soc. Hort. Sci. 131:506-512.

Debnath, S.C., S. Khanizadeh, A.R. Jamieson, and C. Kempler. 2008. Inter simple sequence repeat (ISSR) markers to assess genetic diversity and relatedness within strawberry genotypes. Can. J. Plant Sci. 88:313-322.

Degani, C., L.J. Rowland, J.A. Saunders, S.C. Hokanson, E.L. Ogden, A.G. Goldhirsh, and G.J. Galletta. 2001. A comparison of genetic relationship measures in strawberry (Fragaria $\times$ ananassa Duch.) based on AFLPs, RAPDs, and pedigree data. Euphytica 117:1-12.

Esselink, G.D., M.J.M. Smulders, and B. Vosman. 2003. Identification of cut rose (Rosa hybrida) and rootstock varieties using robust sequence tagged microsatellite site markers. Theor. Appl. Genet. 106:277-286.

Excoffier, L., G. Laval, and S. Schneider. 2005. Arlequin version 3.0: An integrated software package for population genetics data analysis. Evol. Bioinform. Online 1:47-50.

Falush, D., M. Stephens, and J.K. Pritchard. 2007. Inference of population structure using multilocus genotype data: Dominant markers and null alleles. Mol. Ecol. Notes 7:574-578.

Felsenstein, J. 1989. PHYLIP-Phylogeny inference package (version 3.2). Cladistics 5:164-166.

Folta, K.M. and T.M. Davis. 2006. Strawberry genetics and genomics. Crit. Rev. Plant Sci. 25:399-415.

Food and Agriculture Organization of the United Nations. 2008. ProdSTAT. World production quantity. Commodity: Strawberries. 8 Jan. 2008. <http://faostat.fao.org/site/567/default.aspx>.

Galleta, G.J. and J.L. Maas. 1990. Strawberry genetics. HortScience 25:871-878.

Gil-Ariza, D.J., I. Amaya, M.A. Botella, J. Muñoz-Blanco, J.L. Caballero, J.M. López-Aranda, V. Valpuesta, and J.F. SánchezSevilla. 2006. EST-derived polymorphic microsatellites from cultivated strawberry (Fragaria ×ananassa) are useful for diversity studies and varietal identification among Fragaria species. Mol. Ecol. Notes 6:1195-1197.

Graham, J., R.J. McNicol, and J.W. McNicol. 1996. A comparison of methods for the estimation of genetic diversity in strawberry cultivars. Theor. Appl. Genet. 93:402-406.

Gupta, P.K., S. Rustgi, S.R. Sharma, N. Kumar, and H.S. Balyan. 2003. Transferable EST-SSR markers for the study of polymorphism and genetic diversity in bread wheat. Mol. Genet. Genomics 270:315323.

Hadonou, A.M., D.J. Sargent, F. Wilson, C.M. James, and D.W. Simpson. 2004. Development of microsatellite markers in Fragaria, their use in genetic diversity analysis, and their potential for genetic linkage mapping. Genome 47:429-438.

Hancock, J.F. 1999. Strawberries. CAB International, Oxford, UK.

Hancock, J.F., D.H. Scott, and F.J. Lawrence. 1996. Strawberries, p. 419-470. In: Janick, J. and J.N. Moore (eds.). Fruit breeding: Vine and small fruits. Wiley, New York, NY.

Hokanson, K.E., M.J. Smith, A.M. Connor, J.J. Luby, and J.F. Hancock. 2006. Relationships among subspecies of new world octoploid strawberry species, Fragaria virginiana and Fragaria chiloensis, based on simple sequence repeat marker analysis. Can. J. Bot. 84:1829-1841.
James, C.M., F. Wilson, A.M. Hadonou, and K.R. Tobutt. 2003. Isolation and characterisation or polymorphic microsatellites in diploid strawberry ( $F$. vesca L.) for mapping, diversity studies and clone identification. Mol. Ecol. Notes 3:171-173.

Keniry, A., C.L. Hopkins, E. Jewell, B. Morrison, G.C. Spangenberg, D. Edwards, and J. Batley. 2005. Identification and characterization of simple sequence repeat (SSR) markers from Fragaria $\times$ ananassa expressed sequence. Mol. Ecol. Notes 6:319-322.

Kloosterman, A.D., B. Budowle, and P. Daselaar. 1993. PCR-amplification and detection of the human D1S80 VNTR locus: Amplification conditions, population genetics and application in forensic analysis. Intl. J. Legal Med. 105:257-264.

Lerceteau-Köhler, E., G. Guérin, F. Laigret, and B. Denoyes-Rothan. 2003. Characterization of mixed disomic and polysomic inheritance in the octoploid strawberry (Fragaria $\times$ ananassa) using AFLP mapping. Theor. Appl. Genet. 107:619-628.

Lewers, K.S., S.M.N. Styan, S.C. Hokanson, and N.V. Bassil. 2005. Strawberry GenBank-derived and genomic simple sequence repeat (SSR) markers and their utility with strawberry, blackberry, and red and black raspberry. J. Amer. Soc. Hort. Sci. 130:102-115.

Lynch, M. and B. Walsh. 1998. Genetics and analysis of quantitative traits. Sinauer Associates, Sunderland, MA.

Maccaferri, M., M.C. Sanguineti, P. Donini, and R. Tuberosa. 2003. Microsatellite analysis reveals a progressive widening of the genetic basis in the elite durum wheat germplasm. Theor. Appl. Genet. 107:783-797.

Monfort, A., S. Vilanova, T.M. Davis, and P. Arus. 2006. A new set of polymorphic simple sequence repeat (SSR) markers from a wild strawberry (Fragaria vesca) are transferable to other diploid Fragaria species and to Fragaria ×ananassa. Mol. Ecol. Notes 6: 197-200.

Nei, M. 1973. Analysis of gene diversity in subdivided populations. Proc. Natl. Acad. Sci. USA 70:3321-3323.

Nei, M. and W.H. Li. 1979. Mathematical model for studying genetic variation in terms of restriction endonucleases. Proc. Natl. Acad. Sci. USA 76:5269-5273.

Pinto, L.R., K.M. Oliveira, E.C. Ulian, E.A. Franco-Garcia, and A. Pereira de Souza. 2004. Survey in the sugarcane expressed sequence tag database (SUCEST) for simple sequence repeats. Genome 47:795-804.

Pritchard, J.K., M. Stephens, and P. Donnelly. 2000. Inference of population structure using multilocus genotype data. Genetics 155:945-959.

Röder, M.S., V. Korzun, K. Wendehake, J. Plaschke, M.H. Tixier, P. Leroy, and M.W. Ganal. 1998. A microsatellite map of wheat. Genetics 149:2007-2023.

Rousseau-Gueutin, M., E. Lerceteau-Köhler, L. Barrot, D.J. Sargent, A. Monfort, D. Simpson, P. Arús, G. Guérin, and B. DenoyesRothan. 2008. Comparative genetic mapping between octoploid and diploid Fragaria species reveals a high level of colinearity between their genomes and the essentially disomic behavior of the cultivated octoploid strawberry. Genetics 179:2045-2060.

Sánchez-Sevilla, J.F., C. Soria, R. Villalba, D. Gil, J. Gálvez, I. Clavero, J.M. López-Aranda, R. Bartual, and J.J. Medina. 2004. Strawberry germplasm collection at CIFA-Malaga (Spain). Acta Hort. 649:119-122.

Sargent, D.J., J. Clarke, D.W. Simpson, K.R. Tobutt, P. Arus, A. Monfort, S. Vilanova, B. Denoyes-Rothan, M. Rousseau, K.M. Folta, N.V. Bassil, and N.H. Battey. 2006. An enhanced microsatellite map of diploid Fragaria. Theor. Appl. Genet. 112:13491359.

Sargent, D.J., T.M. Davis, K.R. Tobutt, M.J. Wilkinson, N.H. Battey, and D.W. Simpson. 2004. A genetic linkage map of microsatellite, gene-specific and morphological markers in diploid Fragaria. Theor. Appl. Genet. 109:1385-1391.

Sargent, D.J., A.M. Hadonou, and D.W. Simpson. 2003. Development and characterization of polymorphic microsatellite markers from 
Fragaria viridis, a wild diploid strawberry. Mol. Ecol. Notes 3:550552.

Shaw, D.V. 1997. Trait mean depression for second-generation inbred strawberry populations with and without parent selection. Theor. Appl. Genet. 95:261-264.

Shimomura, K. and K. Hirashima. 2006. Development and characterization of simple sequence repeats (SSR) as markers to identify strawberry cultivars (Fragaria $\times$ ananassa Duch.). J. Jpn. Soc. Hort. Sci. 75:399-402.

Sjulin, T.M. and A. Dale. 1987. Genetic diversity of North American strawberry cultivars. J. Amer. Soc. Hort. Sci. 112:375-385.
Tessier, T., J. David, P. This, J.M. Boursiquot, and A. Charrier. 1999. Optimization of the choice of molecular markers for varietal identification in Vitis vinifera L. Theor. Appl. Genet. 98:171-177. Thiel, T., W. Michalek, R.K. Varshney, and A. Graner. 2003. Exploiting EST databases for the development and characterization of gene derived SSR-markers in barley (Hordeum vulgare L.). Theor. Appl. Genet. 106:411-422.

Yong, X., M. Rong-Cai, X. Hua, L. Jian-Ting, and C. Ming-Qing. 2004. Development of SSR markers for the phylogenetic analysis of almond trees from China and the Mediterranean region. Genome 47:1091-1104. 